\author{
Dariusz Siudak \\ Politechnika Łódzka \\ e-mail: dariusz.siudak@p.lodz.pl
}

\title{
CZY PRZEDSIĘBIORSTWO O WYSOKIEJ WARTOŚCI WSPÓLCZYNNIKA SKUPIENIA MA NISKI STOPIEŃ RELACJI W SIECI POWIĄZAŃ WSPÓLNA DYREKCJĄ NA POLSKIM RYNKU KAPITALOWYM?*
}

\section{DO COMPANIES WITH HIGH CLUSTERING COEFFICIENT HAVE LOW DEGREE IN THE NETWORK OF INTERLOCKING DIRECTORATES ON THE POLISH CAPITAL MARKET?}

DOI: 10.15611/nof.2015.3.08

\begin{abstract}
Streszczenie: W artykule podjęto problematykę zależności współczynnika skupienia od stopnia relacji w sieci przedsiębiorstw powiązanych wspólną dyrekcją (interlocking directorates). Badaniem objęto 479 przedsiębiorstw, dla których stopień relacji jest większy od jedności, spośród łącznie 902 przedsiębiorstw notowanych na głównym rynku Giełdy Papierów Wartościowych w Warszawie oraz na rynku NewConnect pod koniec 2014 r. Oceny relacji współczynnika skupienia i liczby połączeń dokonano z wykorzystaniem jednoczynnikowej analizy wariancji (ANOVA) oraz porównaniem relacji dwóch sieciowych współczynników skupienia (1) w sensie Wattsa-Strogatza $\left(C C^{W S}\right)$ oraz w sensie przechodniości $(C)$. Wyniki badania wykazały, że spółki o wysokim współczynniku skupienia mają niski stopień relacji w sieci powiązań przedsiębiorstw na polskim rynku kapitałowym.
\end{abstract}

Słowa kluczowe: sieć, współczynnik skupienia, stopień relacji, wspólna dyrekcja.

Summary: The article looks at the relation of the clustering coefficient and degree in the network of interlocking directorates. The study covered 479 enterprises which degree is over 1 out of 902 companies listed on the main market at the Warsaw Stock Exchange and on the NewConnect at the end of 2014. The relation of the clustering coefficient and degree was assessed using the one-way analysis of variance (ANOVA) and a comparison of two network clustering coefficients, (1) in the sense of Watts-Strogatz $\left(C C^{W S}\right)$ and in the sense of transitivity $(C)$. The analysis led to the conclusion that a company with a high clustering coefficient has low degree in the board network on the Polish capital market.

Keywords: network, clustering coefficient, degree, interlocking directorate.

* Projekt został sfinansowany ze środków Narodowego Centrum Nauki przyznanych na podstawie decyzji numer DEC-2013/11/B/HS4/00466. 


\section{Wstęp}

Sieć powiązań przedsiębiorstw (board network) należy zaliczyć do sieci społecznych (social network), których ogólne charakterystyki różnią się od innych rodzajów sieci, takich jak biologiczne, technologiczne, informacyjne lub geograficzne. Jedną z cech sieci społecznych jest wysoka wartość współczynnika skupienia, co odróżnia je od innych typologii sieci, a także od modelu losowego formowania sieci w sensie grafów losowych Erdösa-Renyi, zaprezentowanych w pracy [Erdös, Renyi 1959]. Wyniki badań $\mathrm{w}$ tym zakresie zostały przedstawione w pracach [Newman, Park 2003; Newman 2010].

W wielu sieciach zaobserwowano odwrotną relację między lokalnym współczynnikiem skupienia a liczbą połączeń uformowanych dla danego wierzchołka w sieci (por. [Dorogovtsev 2010; Jackson 2008; Newman 2010; Ravasz, Barabási 2003; Vázquez, Pastor-Satorras, Vespignani 2002; Szabó, Alava, Kertész 2003]). Na tej podstawie formułujemy następującą hipotezę: $\mathrm{w}$ sieci powiązań przedsiębiorstw wspólną dyrekcją na polskim rynku kapitałowym spółki uzyskują wysoki współczynnik skupienia przy zawarciu relatywnie małej liczby połączeń (niski stopień relacji).

Celem artykułu jest analiza relacji między współczynnikiem skupienia a liczbą formowanych połączeń (stopnia relacji) w sieci powiązań przedsiębiorstw notowanych na polskim rynku kapitałowym. Podstawą tworzonej sieci powiązań przedsiębiorstw jest wspólna rada dyrektorów (interlocking directorates) - członków zarządu i rady nadzorczej. Połączenie między przedsiębiorstwami powstaje w sytuacji, gdy przynajmniej jedna osoba zasiada w radzie dyrektorów obu spółek.

Badaniem objęto wszystkie spółki notowane na podstawowym rynku Giełdy Papierów Wartościowych w Warszawie oraz na rynku NewConnet w grudniu 2014 r. (łącznie 902 przedsiębiorstwa). Ze względu na właściwości współczynnika skupienia ostateczna liczba badanych spółek została ograniczona do 479 (opis współczynnika skupienia oraz przyczyny wyeliminowania części spółek z analizy zamieszczono w punkcie 2).

\section{Stopień relacji i współczynnik skupienia}

Podstawową charakterystyką wierzchołka w sieci jest jego stopień relacji (degree), czyli liczba bezpośrednich relacji równocześnie łączących analizowaną jednostkę $\mathrm{z}$ innymi wierzchołkami w sieci

$$
d_{i}=\sum_{j=1}^{N} a_{i j}(i \neq j),
$$

gdzie: $d_{i}$ - stopień relacji wierzchołka $i ; a_{i j}$ - element nieskierowanej (undirected) macierzy połączeń między węzłami $i \mathrm{i} j$. 
Stopień relacji określa aktywność i zaangażowanie jednostki w zakresie jej bezpośrednich relacji w sieci, które przedsiębiorstwo może do pewnego stopnia kontrolować [Sankowska, Siudak 2015, s. 124]. Charakterystyka liczby bezpośrednich relacji zupełnie pomija stopień i charakter usieciowienia węzłów, z którymi jednostka jest powiązana. Innymi słowy, ignorowana jest konstrukcja sieci wychodząca poza obszar bezpośrednich relacji.

Stopień relacji określa liczbę krawędzi wychodzących z wierzchołka (liczba sąsiadów), koncepcja współczynnika skupienia oparta jest zaś na połączeniach tych sąsiadów. Lokalny współczynnik skupienia określa przechodniość w sąsiedztwie analizowanego wierzchołka w sieci [Thadakamalla, Kumara, Albert 2008, s. 11-17]. Współczynnik ten wskazuje na poziom gęstości obszaru wokół wierzchołka w sieci [Borgatti, Everett, Johnson 2013, s. 156]. Współczynnik skupienia $C C_{i}$ dla wierzchołka $i$ stanowi relację między liczbą krawędzi zaobserwowanych między sąsiadami wierzchołka $i\left(m_{i}\right)$ a maksymalną możliwą liczbą krawędzi między sąsiednimi wierzchołkami węzła $i$, których liczba w sieci nieskierowanej wynosi $\left(\begin{array}{c}d_{i} \\ 2\end{array}\right)=\frac{d_{i}\left(d_{i}-1\right)}{2}$, tworzących trójkąty (pętle o długości 3) zawierające wierzchołek $i$ z liczbą połączeń równą $d_{i}$

$$
C C_{i}=\frac{m_{i}}{\frac{d_{i}\left(d_{i}-1\right)}{2}}=\frac{2 m_{i}}{d_{i}\left(d_{i}-1\right)} \quad\left(d_{i} \geq 2\right),
$$

gdzie: $m_{i}$ - liczba obserwowanych połączeń między sąsiednimi wierzchołkami węzła $i, d_{i}$ - stopień relacji węzła $i$.

Współczynnik ten jest nieokreślony dla tych wierzchołków, których stopień relacji $d_{i}$ wynosi 1 lub 0 (wierzchołek izolowany). Lokalny współczynnik skupienia zawiera się w zakresie $0 \leq C C_{i} \leq 1^{3}$ i określa prawdopodobieństwo występowania krawędzi między dwoma wierzchołkami, bezpośrednio połączone z węzłem $i$. Przykładowo, jeżeli dla trójki wierzchołków $a, b, c$ występują połączenia między $a$ i $b$ oraz $b$ i $c$, to prawdopodobne jest istnienie krawędzi łączącej wierzchołki $a$ i $c$. Oznacza to wysoką gęstość trójkąta $a b c$. W odniesieniu do sieci społecznych nadawana jest temu następująca interpretacja: przyjaciel twojego przyjaciela jest jednocześnie twoim przyjacielem. Graficzną ilustrację lokalnego współczynnika skupienia $\left(C C_{i}\right)$ przedstawiono na rys. 1.

Zdefiniowany równaniem (2) lokalny współczynnik skupienia stanowi podstawę sieciowego współczynnika skupienia (network clustering coefficient) w sensie Wattsa-Strogatza $\left(C C^{W S}\right.$ ) [Watts, Strogatz 1998] w postaci średniej $C C_{i}$ dla wszystkich pojedynczych wierzchołków w sieci [Sankowska, Siudak 2016].

$$
C C^{W S}=\frac{\sum_{i=1}^{N} C C_{i}}{N},
$$

gdzie $N$ - liczba wierzchołków w sieci. 


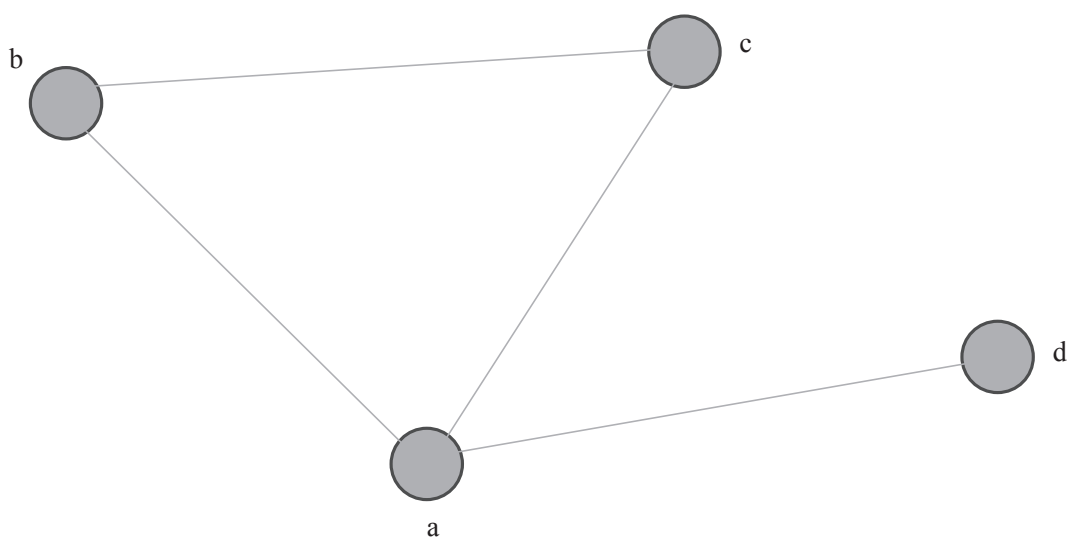

Rys. 1. Interpretacja graficzna współczynnika skupienia. Dla wierzchołków: $b, c C C_{i}=1\left(m_{i}=1\right.$; $\left.d_{i}=2\right)$; dla wierzchołka $a C C_{i}=1 / 3\left(m_{i}=1 ; d_{i}=3\right)$; dla wierzchołka $d$ współczynnik jest nieokreślony. Źródło: opracowanie własne na podstawie [Caldarelli 2013, s. 16].

Sieciowy współczynnik skupienia $\left(C C^{W S}\right)$ stanowi podstawową kategorię analizy zjawiska sieci małych światów (small-world networks) obserwowanego w wielu sieciach społecznych (social networks), polegającego na tym, że w sieci składającej się z bardzo dużej liczby węzłów średnia najkrótsza odległość między wierzchołkami (geodesic distance) w sieci jest bardzo krótka ze względu na występujące między węzłami w sieci liczne skróty o szerokim zakresie i wraz ze wzrostem liczby wierzchołków w sieci odległość ta wzrasta w tempie logarytmicznym [Siudak 2015]. Zagadnienie małego świata w sieciach stanowi przedmiot rozważań w pracach: [Watts, Strogatz 1998; Watts 1999a; 1999b; Humphries, Gurney 2008; Jia, Kulkarni 2013; Strogatz 2001; Kogut (red.) 2012].

W literaturze dotyczącej sieci występuje też inna postać - w odniesieniu do $C C^{W S}$ opisanego relacją (3) - sieciowego współczynnika skupienia, określanego mianem przechodniości (transitivity):

$$
C=\frac{3 \times \text { liczba pętli w sieci o długości } 3}{\text { liczba wierzchotków połączonych } w \text { trójki }}
$$

Współczynnik przechodniości wskazuje na średnie dla całej sieci prawdopodobieństwo występowania połączenia między bezpośrednimi sąsiadami wierzchołka. Wartość tego współczynnika równa 1 oznacza, że sieć składa się z trójkątów [Sankowska, Siudak 2016], tj. wierzchołek oraz ich dwa połączone krawędzią sąsiednie węzły.

Relacja zachodząca między dwoma rodzajami sieciowego współczynnika skupienia $\left(C C^{W S}\right.$ a $\left.C\right)$ sprowadza się do postaci $C$ tożsamej z ilorazem średniej dla całej sieci licznika do średniej mianownika lokalnego współczynnika skupienia $C C_{i}$ określonego relacją (2) i stanowiącego podstawę $C C^{W S}$ [Dorogovtsev 2010]: 


$$
C \equiv \frac{\left\langle m_{i}\right\rangle}{\left\langle d_{i}\left(d_{i}-1\right) / 2\right\rangle},
$$

gdzie symbol $\langle\square\rangle$ oznacza wartość średnią.

Jeżeli wystąpi różnica

$$
C C^{w S} \neq C,
$$

to lokalny współczynnik skupienia $\left(C C_{i}\right)$ zależny jest od stopnia relacji poszczególnych węzłów (por. [Dorogovtsev 2010, s. 27]). Natomiast istotna nierówność

$$
C C^{W S}>C
$$

oznacza zmniejszającą się wartość $C C_{i}$ wraz ze wzrostem liczby zawieranych połączeń w sieci (d) (por. [Jackson 2008, s. 67]). Nierówność (7) spełniona jest przez zdecydowaną większość sieci społecznych. Przegląd wyników badań w tym zakresie przedstawiono w pracy [Newman 2010, s. 237].

\section{Analiza relacji lokalnego współczynnika skupienia i liczby połączeń $w$ sieci}

Najpierw przeprowadzono badanie korelacyjne liniowej zależności między lokalnym współczynnikiem skupienia a stopniem relacji poszczególnych przedsiębiorstw. Współczynnik korelacji Pearsona wyniósł $r=-0,074$. Ujemny liniowy związek między powyższymi zmiennymi może wskazywać na uzyskiwanie większych wartości współczynnika skupienia przy zmniejszającej się liczbie zawieranych relacji. Korelacja ta nie jest istotna statystycznie $(p=0,106)$ na poziomie istotności $\alpha=0,05$, stąd wymagana jest pogłębiona analiza sformułowanego problemu badawczego.

Porównaniu poddamy wyniki w zakresie sieciowego współczynnika skupienia w sensie Wattsa-Strogatza (relacja (3)) oraz w sensie przechodniości zdefiniowanego w postaci równania (4). Dla sieci powiązań przedsiębiorstw uzyskano relację $C C^{W S}>C$, otrzymując wartości $C C^{W S}=0,602$ oraz $C=0,526$. Ponieważ różnica $\left(C C^{W S}-C=0,602-0,526=0,076\right)$ nie jest znaczna, można na tej podstawie przypuszczać, że tylko częściowo lokalny współczynnik skupienia jest zależny od stopnia relacji.

Analizowane przedsiębiorstwa (ich liczba wynosiła 479), których stopień relacji jest większy od jedności, podzielono na cztery grupy utworzone na podstawie kwartyli współczynnika skupienia, tj.:

- Grupę 1: $<\min . C C_{i} \div 1$ kwartyl $C C_{i}$ ).

- Grupę 2: $<1$ kwartyl $C C_{i} \div 2$ kwartyl $C C_{i}$ ).

- Grupę 3: $<2$ kwartyl $C C_{i} \div 3$ kwartyl $C C_{i}$ ). 
- $\quad$ Grupę 4: $<3$ kwartyl $C C_{i} \div \max . C C_{i}$ ).

Za pomocą jednoczynnikowej analizy wariancji (jednoczynnikowa ANOVA) zostanie przeprowadzona weryfikacja hipotezy o równości średniej stopnia relacji między czterema grupami przedsiębiorstw:

$\mathrm{H}_{0}: \mu_{1}=\mu_{2}=\mu_{3}=\mu_{4}-$ brak różnic $\mathrm{w}$ wartościach średnich stopnia relacji;

$\mathrm{H}_{1}: \exists j_{1} j_{2}: \mu_{j_{1}} \neq \mu_{j_{2}}-$ przynajmniej dwie grupy różnią się względem średniej stopnia relacji.

W tabeli 1 zamieszczono statystykę testu $F$.

Tabela 1. Statystyka testu F

\begin{tabular}{|c|c|c|c|c|c|}
\hline Specyfikacja & $\begin{array}{c}\text { Sumy kwadratów } \\
\text { (SS) }\end{array}$ & $d f$ & $\begin{array}{c}\text { Średni kwadrat } \\
(M S)\end{array}$ & $\mathrm{F}$ & Istotność $(p)$ \\
\hline Pomiędzy grupami & 691,40 & 3 & 230,47 & \multirow{3}{*}{25,443} & \multirow{3}{*}{0,000} \\
\hline Wewnątrz grup & 4302,59 & 475 & 9,06 & & \\
\hline Razem & 4993,99 & 478 & & & \\
\hline
\end{tabular}

Źródło: obliczenia własne na podstawie badań empirycznych.

Bieżący efekt: $\mathrm{F}(3,475)=25,443, \mathrm{p}=, 00000$

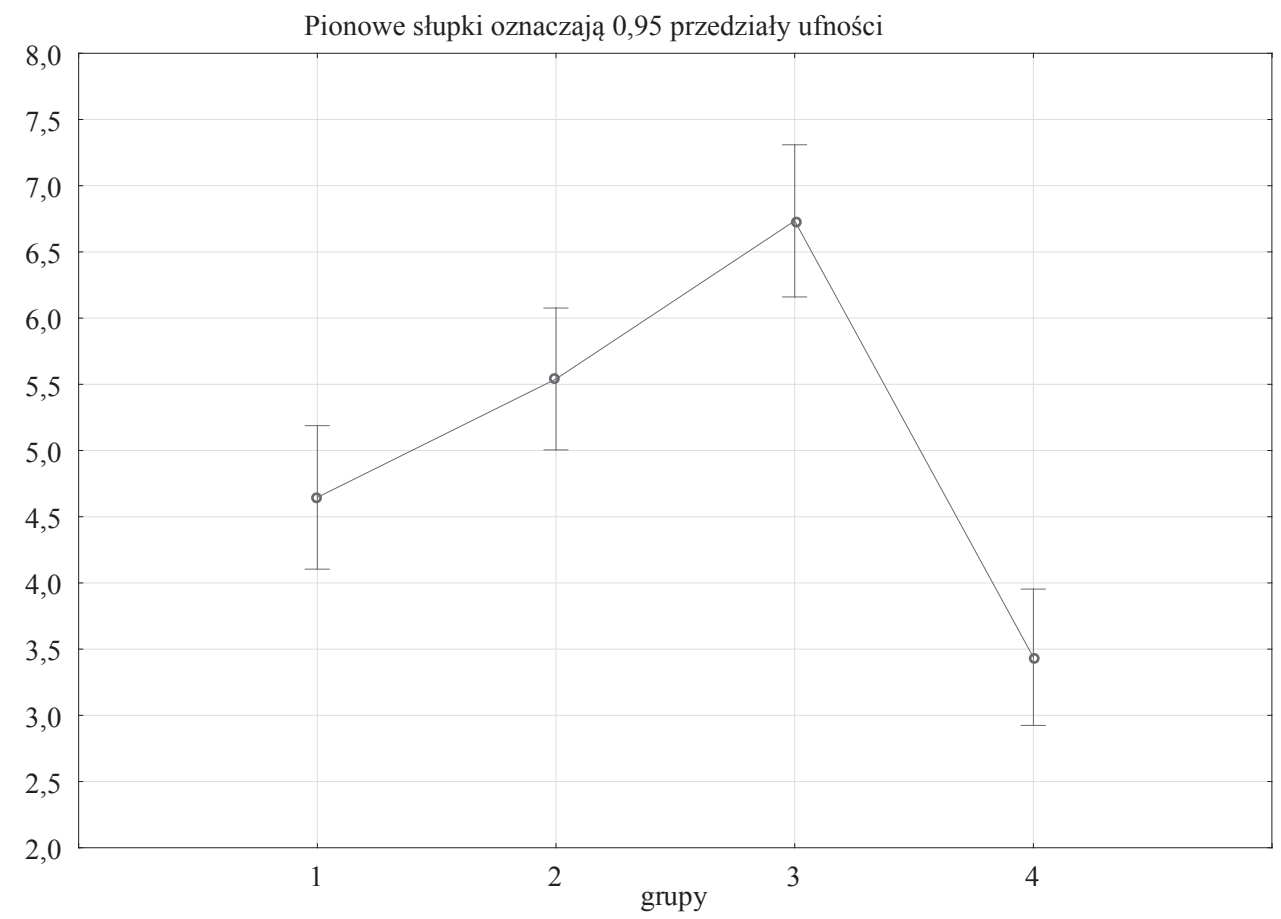

Rys. 2. Wykres interakcji średnich stopnia relacji w podziale na grupy względem kwartyli $C C_{i}$

Źródło: opracowanie własne na podstawie badań empirycznych. 
Na podstawie istotnej statystycznie na poziomie istotności $\alpha=0,001$ statystyki testu $F(3 ; 475)=25,4$ należy przyjąć hipotezę $\mathrm{H}_{1}$. Na rysunku 2 przedstawiono wykres interakcji średnich stopnia relacji w podziale na grupy na podstawie kwartyli lokalnego współczynnika skupienia $\left(C C_{i}\right)$.

Obserwowany jest wzrost średniej stopnia relacji dla pierwszych trzech grup, a następnie znaczny spadek dla przedsiębiorstw z czwartej grupy, o najwyższym współczynniku skupienia. Oznacza to, że początkowo wzrostowi współczynnika skupienia towarzyszy wzrost stopnia relacji, aczkolwiek spółki z największą wartością tego współczynnika (czwarta grupa $C C_{i}$ ) są w stanie osiągnąć ten wynik przy relatywnie niskiej liczbie połączeń (stopniu relacji). Statystyki opisowe stopnia relacji względem grup zamieszczono w tab. 2. Łatwo zaobserwować blisko dwukrotnie mniejszą średnią liczbę połączeń przedsiębiorstw o najwyższym współczynniku skupienia (czwarta grupa) $-\langle d\rangle=3,439-$ a spółkami z grupy trzeciej $-\langle d\rangle=6,736$. Jednocześnie średni stopień relacji spółek z grupy o najwyższym współczynniku skupienia jest również mniejszy od średniej wartości liczby połączeń dla całej analizowanej zbiorowości (479 spółek).

Tabela 2. Statystyki opisowe stopnia relacji dla przyjętego podziału

\begin{tabular}{|l|c|c|c|r|r|r|}
\hline \multirow{2}{*}{$\begin{array}{c}\text { Wyszczegól- } \\
\text { nienie }\end{array}$} & \multirow{2}{*}{$n$} & \multicolumn{5}{|c|}{ Stopień relacji $-d$} \\
\cline { 3 - 7 } & & $\begin{array}{c}\text { średnia } \\
\langle\mathrm{d}\rangle\end{array}$ & $\begin{array}{c}\text { odchylenie } \\
\text { standardowe }\end{array}$ & $\begin{array}{c}\text { błąd } \\
\text { standardowy }\end{array}$ & $-95,0 \%$ & $+95,0 \%$ \\
\hline Ogółem & 479 & 5,004 & 3,232 & 0,148 & 4,714 & 5,294 \\
\hline Grupa 1 & 119 & 4,647 & 3,336 & 0,306 & 4,041 & 5,253 \\
\hline Grupa 2 & 122 & 5,541 & 3,062 & 0,277 & 4,992 & 6,090 \\
\hline Grupa 3 & 106 & 6,736 & 3,290 & 0,320 & 6,102 & 7,369 \\
\hline Grupa 4 & 132 & 3,439 & 2,342 & 0,204 & 3,036 & 3,843 \\
\hline
\end{tabular}

Źródło: obliczenia własne na podstawie badań empirycznych.

Przyjęcie hipotezy $\mathrm{H}_{1}$ oznacza istotną statystycznie różnicę w wartościach średnich stopnia relacji między co najmniej dwiema grupami. Zatem przyjęcie hipotezy $\mathrm{H}_{1}$ nie musi obligatoryjnie wskazywać na istotne różnice między wszystkimi grupami. Identyfikacji, między którymi klasami występują istotne statystycznie różnice w średnich stopnia relacji, dokonamy za pomocą testu Scheffego (typu post-hoc). W tabeli 3 zamieszczono przybliżone prawdopodobieństwa testu Scheffego.

Tabela 3. Przybliżone prawdopodobieństwa dla testu Scheffego (post-hoc)*

\begin{tabular}{|c|c|c|c|c|}
\hline Grupa & 1 & 2 & 3 & 4 \\
\hline 1 & & 0,152 & $\mathbf{0 , 0 0 0}$ & $\mathbf{0 , 0 1 9}$ \\
\hline 2 & 0,152 & & $\mathbf{0 , 0 3 1}$ & $\mathbf{0 , 0 0 0}$ \\
\hline 3 & $\mathbf{0 , 0 0 0}$ & $\mathbf{0 , 0 3 1}$ & & $\mathbf{0 , 0 0 0}$ \\
\hline 4 & $\mathbf{0 , 0 1 9}$ & $\mathbf{0 , 0 0 0}$ & $\mathbf{0 , 0 0 0}$ & \\
\hline
\end{tabular}

* Pogrubionym drukiem zaznaczono $\mathrm{p}<0,05$.

Źródło: obliczenia własne na podstawie badań empirycznych. 
Jedynie między pierwszą i drugą grupą nie występuje statystycznie istotna różnica $\mathrm{W}$ średnich stopnia relacji na poziomie istotności $\alpha=0,05$. W pozostałych porównaniach obserwujemy przybliżone prawdopodobieństwa na poziomie $p<0,05$ (między grupami trzecią i czwartą, a także pierwszą i trzecią, drugą i czwartą $p$ $<0,01)$. Różnica w średniej wartości stopnia relacji między grupą przedsiębiorstw o najwyższej wartości współczynnika skupienia a pozostałym grupami jest zatem obserwacją istotną statystycznie.

\section{Podsumowanie}

Dla przedsiębiorstw uszeregowanych rosnąco względem lokalnego współczynnika skupienia początkowo obserwowany jest wzrost stopnia relacji, spółki o największej wartości współczynnika skupienia osiągają zaś ten rezultat przy relatywnie mniejszej liczbie zawieranych połączeń z innymi przedsiębiorstwami w sieci. Pozytywnie została zweryfikowana hipoteza sformułowana we wprowadzeniu, stąd odpowiedź na pytanie zawarte $w$ tytule artykułu jest twierdzące.

Na podstawie wysokiej wartości sieciowego współczynnika skupienia w sensie zarówno W-S, jak i przechodniości, co stanowi cechę charakterystyczną dla większości sieci społecznych, można stwierdzić nieefektywną strukturę sieci powiązań przedsiębiorstw wspólną dyrekcją ze względu na optymalizację przepływu informacji. Większość spółek charakteryzuje wysoka wartość lokalnego współczynnika skupienia, co sprawia, że w wyniku utworzonych powiązań występuje redundancja informacji. Przykładowy wycinek sieci, zaprezentowany na rys. 1, przedstawia sytuację, kiedy spółka b) ma możliwość uzyskania informacji o spółce a) i c) z dwóch źródeł: bezpośrednio od tych podmiotów, jak również pośrednio, od spółki c) o spółce a) i odwrotnie. Wynika to z bezpośredniej relacji między spółkami a) i c). Ten sam schemat przepływu informacji do spółki b) można przypisać podmiotom a) i c) ze względu na występującą zamkniętą pętlę o długości 3 między wierzchołkami a), b) i c). Kształtowanie relacji między spółkami a) i c) przez podmiot b) - tj. likwidacja połączenia między tymi wierzchołkami - jest wysoce ograniczone, stąd spółka b), chcąc efektywnie wykorzystać zaangażowane zasoby w tworzone relacje w sieci powiązań przedsiębiorstw przy jednoczesnym ograniczeniu redundantności uzyskiwanych informacji, powinna zlikwidować połączenie ze spółką c), zastępując je utworzeniem więzi z innym przedsiębiorstwem w sieci'.

$\mathrm{Z}$ wykresu interakcji średnich stopnia relacji w podziale na grupy względem kwartyli $C C_{i}$ (por. rys. 2) wynika, że wyższy współczynnik skupienia uzyskują spółki, które zawierają największą lub najmniejszą liczbę relacji. Na tej podstawie można wysunąć wniosek, że to nie liczba zawieranych relacji z innymi przedsiębiorstwami w sieci powiązań rad dyrektorów, lecz odpowiednio dobrane połącze-

1 Likwidacja relacji ze spółką a) byłaby gorszym rozwiązaniem ze względu na jej połączenie ze spółką d). 
nia wpływają na efektywność tworzonych relacji pod względem nieredundantnego przepływu informacji.

W odniesieniu do analizowanej sieci nie wykryto odwrotnej relacji między lokalnym współczynnikiem skupienia a liczbą połączeń (stopniem relacji), co stanowi charakterystykę dla wielu sieci społecznych. Oznacza to odmienny sposób formowania sieci, niż ma to miejsce w modelach sieci hierarchicznych (por. [Ravasz, Barabasi 2003]). Model konstrukcji sieci powiązań przedsiębiorstw wspólną dyrekcją wymaga zatem szerszych analiz studialnych, wskazując tym samym kierunek dalszych badań.

\section{Literatura}

Borgatti S., Everett M., Johnson J.C., 2013, Analyzing Social Networks, Sage, London.

Caldarelli G., 2013, Scale-Free Networks. Complex Webs in Nature and Technology, Oxford University Press, Oxford.

Dorogovtsev S., 2010, Lectures on Complex Networks, Oxford University Press, Oxford.

Erdös P., Renyi A., 1959, On random graphs. I, Publ. Math., 6, s. 290-297.

Humphries M., Gurney K., 2008, Network 'small-world-ness': A quantitative method for determining canonical network equivalence, PLoS ONE, vol. 3, issue 4, s. 1-10.

Jackson M., 2008, Social and Economic Networks, Princeton University Press, Oxford.

Jia T., Kulkarni R.V., 2003, On the structural properties of small-world networks with range-limited shortcut links, Physica A: Statistical Mechanics and its Applications, 392(23), s. 6118-6124.

Kogut B. (red.) (2012), The small worlds of corporate governance, MIT Press, Cambridge.

Newman M., 2010, Networks. An Introduction, Oxford University Press, New York.

Newman M., Park J., 2003, Why social networks are different from other types of networks, Physical Review E, 68, s. 36122/1-36122/8.

Ravasz E., Barabási A., 2003, Hierarchical organization in complex networks, Physical Review E, 67, s. $26112 / 1-26112 / 7$.

Sankowska A., Siudak D., 2015, Miary analizy sieciowej w ocenie strategii interlockingu - powiazania rady dyrektorów, Nauki o Finansach, 1(22), s. 120-135, Wrocław.

Sankowska A., Siudak D., 2016, The Small World Phenomenon and Assortative Mixing in Polish Corporate Board and Director Networks, Physica A, 443, s. 309-315.

Siudak D., 2015, Struktura społeczności sieci powiązań rad dyrektorów przedsiębiorstw na polskim rynku kapitałowym, Przegląd Statystyczny, 62/2, s. 183-197.

Strogatz S.H., 2001, Exploring complex networks, Nature, 410, s. 268-276.

Szabó G., Alava M., Kertész J., 2003, Structural transitions in scale-free networks, Physical Review E, 67, s. 056102/1-056102/5.

Thadakamalla H., Kumara S., Albert R., 2008, Complexity and Large-Scale Networks, [w:] Operations Research and Management Science. Handbook, (red.) Ravindran A.R., Taylor and Francis Group.

Vázquez A., Pastor-Satorras R., Vespignani A., 2002, Large-scale topological and dynamical properties of the Internet, Physical Review E, 65, s. 066130/1-066130/12.

Watts D.J., 1999a, Networks, Dynamics, and the small-world phenomenon, American Journal of Sociology, 105, s. 493-527. 
Watts D.J., 1999b, Small-worlds. The Dynamic of Networks between Order and Randomness, Princeton University Press, New Jersey.

Watts D.J., Strogatz S.H., 1998, Collective dynamics of 'small-world' networks, Nature, 393, s. 440-442 . 